\title{
STRATEGI PEMASARAN UNTUK MENARIK MINAT MASYARAKAT PADA MENU TRADISIONAL SEMANGGI - SURABAYA
}

\author{
Citra Anggraini Tresyanto \\ Program Studi Manajemen \\ Fakultas Ekonomi Universitas Katolik Darma Cendika \\ Jalan Dr. Ir. H. Soekarno 201, Surabaya
}

\begin{abstract}
Modern menu capable of easily sliding the existence of traditional menus first existing in the community. It also makes the young generation does not recognize traditional menus available. One example is the typical menu is a menu Semanggi Surabaya. People are starting trouble finding the menu, and existence without innovation has blurred its presence in the community, especially the younger generation. It is unfortunate if this clover menu should disappear from the heritage of traditional culinary riches. But there must also be the right strategy for the menu clover to stay alive in the community. Lovelock and Wright (2002: 13-15) developed the marketing mix (marketing mix) into integrated service management by using an approach $8 P$ (elements Product, Place, cyberspace, and time, and education Promotion, Price and other user outlays, Process, Productivity and quality, People, Physical evidence). The $8 P$ approach is certainly able to assess and establish new strategies appropriate for the development of clover menu. With modernization and government intervention products that facilitate the sellers, the presence of clover menu will continue to exist in society.
\end{abstract}

\begin{abstract}
ABSTRAK
Menu modern mampu dengan mudahnya menggeser keberadaan menu tradisional yang lebih dulu sudah ada di masyarakat. Hal ini juga membuat para generasi muda tidak mengenali menu-menu tradisional yang ada. Salah satu contohnya adalah menu khas Surabaya yaitu menu semanggi. Masyarakat mulai kesulitan mencari menu tersebut, dan keberadaannya yang tanpa inovasi semakin mengaburkan keberadaannya di tengah masyarakat, terlebih generasi muda. Sangat disayangkan apabila menu semanggi ini harus hilang dari warisan kekayaan kuliner tradisional. Namun juga harus ada strategi yang tepat agar menu semanggi tetap hidup di masyarakat. Lovelock and Wright (2002: 13-15) mengembangkan bauran pemasaran (marketing mix) menjadi integrated service management dengan menggunakan pendekatan 8P (Product elements, Place, cyberspace, and time, Promotion and education, Price and other user outlays, Process, Productivity and quality, People, Physical evidence). Pendekatan 8P ini dipastikan mampu mengkaji dan membentuk strategi baru yang tepat untuk pengembangan menu semanggi. Dengan modernisasi produk dan campur tangan pemerintah kota yang memfasilitasi para penjual, maka keberadaan menu semanggi akan terus eksis di masyarakat.
\end{abstract}

Keywords: marketing mix, traditional menu, culinary heritage 


\section{PENDAHULUAN}

Menu-menu modern semakin lama semakin gencar membobardir menu-menu tradisional, sehingga menu tradisional mulai kehilangan pasar. Tidak dapat disalahkan bahwa menu modern berkembang sangat pesat sebagai salah satu akibat dari globalisasi. Inovasi menu modern sangat menarik minat masyarakat, mulai dari inovasi rasa, tampilan makanan, nama makanan hingga inovasi pemasaran yang dilakukan semakin membuat menu tradisional kehilangan minat di hati masyarakat. Ditambah lagi jika menu modern tersebut berasal dari luar negeri, hal ini akan menambah nilai jual menu modern tersebut. Karena masyarakat masih memiliki anggapan bahwa dengan mengkonsumsi menu modern maka kualitas hidup mereka dalam hal prestigious juga akan berdampak positif. Sebagai contoh menu modern untuk kategori makanan ringan atau snack yang kini banyak diminati oleh masyarakat adalah Kebab yang berasal dari Negara Timur Tengah, Pizza dan Burger yang berasal dari Negera Barat, Pancakes dan Cupcakes yang masih berasal dari Negara Barat, dan beberapa menu modern lainnya. Menu tradisional untuk kategori yang sama seperti serabi, dawet, bubur Madura, dan beberapa menu lainnya mulai kehilangan minat di masyarakat. Belum lagi menu makanan untuk kategori lainnya seperti Pecel, Tahu Tek, Bubur Manado dan lain sebagainya. Bahkan saat ini ada beberapa menu makanan tradisional yang mulai punah keberadaanya karena cukup sulit untuk mencari penjual makanan tersebut, salah satunya adalah makanan tradisional Semanggi Surabaya (biasa disebut Semanggi Suroboyo).
Semanggi Surabaya merupakan makanan tradisional yang sangat khas dimiliki oleh kota Surabaya. Jika menu tradisional lainnya dapat diketemukan di seluruh wilayah Indonesia, seperti Masakan Padang, Pecel, Sate, Soto dan sebagainya, namun tidak dengan menu Semanggi ini. Menu Semanggi ini hanya ada di Kota Surabaya dan tidak diketemukan di wilayah lain. Sesungguhnya hal ini merupakan kekayaan lokal yang perlu dilestarikan agar keberadaannya tidak lekang dimakan jaman.

Saat ini persaingan di antara kedua kelompok menu, yaitu menu tradisional dan menu modern sudah tidak dapat terelakkan. Untuk dapat bersaing dengan menu modern, menu tradisional mau tidak mau dan suka tidak suka harus mengikuti perubahan selera konsumen baik secara rasa, tampilan makanan dan strategi pemasarannya. Hipotesis Henderson (dalam Ferdinand, 2000) menggambarkan persaingan sebagai sebuah sistem hubungan (system of relationship) di mana perusahaan hanya dapat eksis dan bertahan, bila mereka mempunyai keunggulan-keunggulan unik (unique advantages) dibandingkan dengan lawannya. Hal ini juga dapat diterapkan dalam strategi pemasaran untuk menu tradisional.

\section{TINJAUAN PUSTAKA}

Aktivitas manajemen pemasaran adalah aktivitas manajerial yang diarahkan untuk merencanakan, menganalisis, melaksanakan, dan mengendalikan seluruh elemen-elemen strategi pemasaran yang lebih dikenal dengan bauran pemasaran atau marketing mix untuk menghasilkan kinerja-kinerja usaha (Ferdinand, 2000). 
Ohmae (dalam Ferdinand, 2000) juga mengemukakan bahwa pengembangan strategi pemasaran yang dilakukan perusahaan melalui berbagai pendekatan yang memfokus pada pengembangan differensiasi atau penciptaan berbagai "point of differentiation" dilakukan bukan hanya untuk menyamai "value" yang dihasilkan oleh pesaing bagi pelanggannya, tetapi juga untuk menyajikan nilai lebih atau "superior value" yang diperoleh melalui berbagai pengembangan inovatif. Karena itu sasaran pengembangan strategi adalah menghasilkan "superior value" atau pelayanan pelanggan yang lebih baik daripada apa yang dilakukan oleh pesaing.

Karena itu untuk menarik kembali minat masyarakat terhadap Semanggi, tidak hanya mementingkan soal rasa dan tampilan makanan namun juga pelayanan penjual kepada masyarakat. Sehingga masyarakat tidak hanya akan mendapat kepuasan semata namun juga merasakan "value" yang berbeda dari pelayanan yang diberikan. Value tersebut dapat berupa banyak hal seperti kebanggaan karena ikut memiliki dan melestarikan kekayaan lokal kota Surabaya serta semakin bertumbuhnya perasaan cinta tanah kelahiran dengan ikut menjaga agar jangan sampai diakui keberadaannya sebagai milik negara lain.

Dalam sebuah persaingan dibutuhkan strategi untuk terus unggul. Strategi yang digunakan berupa alat pemasaran. Ada beragam alat pemasaran pada dunia binis namun sebenarnya tidak semua alat pemasaran dapat dengan mudah diaplikasikan. Alat pemasaran yang dapat membantu menciptakan suatu strategi pemasaran yang ampuh salah satunya adalah marketing mix (bauran pemasaran).
Kotler (2005a: 18-21) menerangkan bahwa bauran pemasaran merupakan seperangkat alat pemasaran yang digunakan perusahaan untuk mencapai tujuan pemasaran dalam memenuhi target pasarnya. Seperangkat alat tersebut menggunakan komponen variabel product, price, place, dan promotion (4P). Namun, bauran pemasaran dengan empat komponen yaitu product, price, place, dan promotion (4P) terus berkembang mengiringi tuntutan pasar dan sesuai dengan perubahan perilaku konsumen yang terjadi.

Lovelock and Wright (2002: 13-15) mengembangkan bauran pemasaran (marketing mix) menjadi integrated service management dengan menggunakan pendekatan 8P, yaitu:

1. Product elements adalah semua komponen dari kinerja layanan yang menciptakan nilai bagi pelanggan.

2. Place, cyberspace, and time adalah keputusan manajemen mengenai kapan, di mana, dan bagaimana menyajikan layanan yang baik.

3. Promotion and education adalah semua aktivitas komunikasi untuk membangun persepsi pelanggan yang dikehendaki oleh perusahaan atas layanan spesifik yang diberikan perusahaan.

4. Price and other user outlays adalah pengeluaran uang, waktu, dan usaha yang dikorbankan pelanggan dalam membeli dan mengkonsumsi produk dan layanan yang perusahaan tawarkan.

5. Process adalah suatu metode pengoperasian atau serangkaian tindakan yang diperlukan untuk menyajikan produk dan layanan yang baik kepada pelanggan. 
6. Productivity and quality, produktivitas adalah sejauh mana efisiensi masukan-masukan layanan ditransformasikan ke dalam hasil-hasil layanan yang dapat menambah nilai bagi pelanggan. Sedangkan kualitas adalah derajat suatu layanan yang dapat memuaskan pelanggan karena dapat memenuhi kebutuhan, keinginan, dan harapan.

7. People adalah pelanggan dan karyawan yang terlibat dalam kegiatan memproduksi produk dan layanan (service production).

8. Physical evidence adalah perangkat-perangkat yang diperlukan dalam menyajikan secara nyata kua- litas produk dan layanan kepada konsumen.

\section{METODE PENELITIAN}

Penelitian ini menggunakan teknik analisis data kualitatif (Kriyantono, 2006: 192) yang dimulai dari berbagai analisis berbagai data yang berhasil dikumpulkan peneliti di lapangan seperti hasil observasi dan wawancara, serta dokumen-dokumen yang berhasil dikumpulkan.

Selain itu penelitian ini juga mengacu pada model analisis interaktif yang dikembangkan oleh Miles dan Huberman (Soegiyono, 2007). Bagan model analisis seperti terlihat pada Gambar 1.

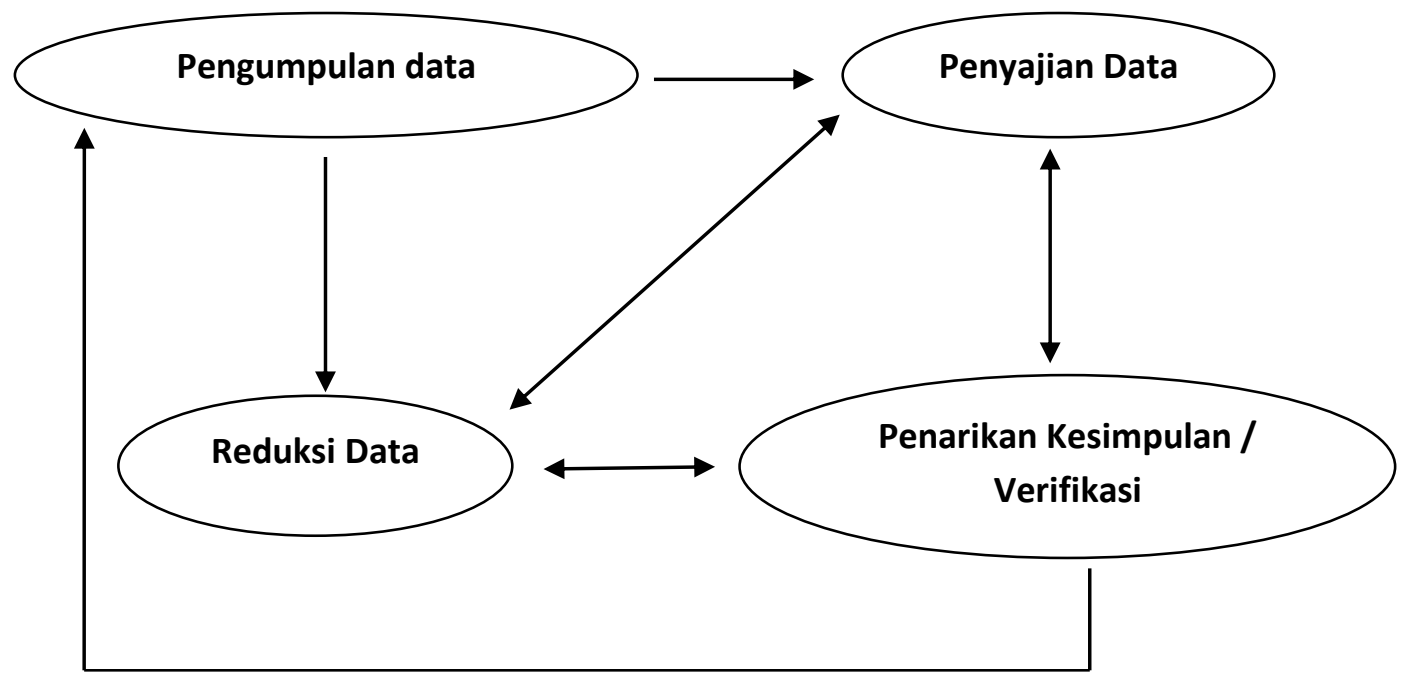

Gambar 1

Analisis Data Kualitatif Model Interaktif(Miles dan Huberman)

Sumber: Soegiyono (2007) 
Penjelasan bagan dari Gambar 1 adalah sebagai berikut:

\section{Pengumpulan Data}

Merupakan tahap mengumpulkan data yang diperoleh dari hasil wawancara, observasi, penelitian kepustakaan dan dokumentasi serta data sekunder lainnya yang berhasil diperoleh.

2. Reduksi Data

Proses reduksi diartikan sebagai proses pemilihan, pemusatan perhatian pada penyederhanaan, pengabstrakan dan transformasi data "kasar" yang muncul dari catatancatatan tertulis di lapangan.

3. Penyajian Data

Langkah berikutnya adalah penyajian data yang dimaknai sebagai sekumpulan informasi yang tersusun yang memberi kemungkinan adanya pengambilan tindakan. Dengan mencermati penyajian data ini, maka akan dapat dipahami apa yang sedang terjadi dan apa yang harus dilakukan.

\section{Penarikan Kesimpulan}

Kegiatan keempat adalah menarik kesimpulan dan melakukan verifikasi.

Dari permulaan pengumpulan data, seseorang penganalisis kualitatif mulai mencari arti benda-benda, mencatat keteraturan, pola-pola penjelasan, konfigurasi-konfigurasi yang mungkin. Sedangkan verifikasi merupakan tinjauan ulang pada catatan-catatan lapangan, dengan kata lain makna yang muncul dari data harus diuji kebenarannya (validitasnya). Verifikasi dalam penelitian dilakukan secara kontinyu sepanjang penelitian verifikasi oleh peneliti, sehingga terbentuk proposisi tertentu yang bisa mendukung teori ataupun penyempurnaan teori.

\section{HASIL PENELITIAN DAN PEMBAHASAN}

Hasil pengolahan data dengan pendekatan $8 \mathrm{P}$ melalui observasi, pengamatan dan dokumen yang diperoleh adalah seperti berikut ini.

\begin{tabular}{|c|c|c|}
\hline No & Marketing Mix 8P & Hasil Pengolahan Data \\
\hline 1. & Product Elements & $\begin{array}{l}\text { Masyarakat menggolongkan } \\
\text { Semanggi adalah makanan } \\
\text { sejenis dengan Gado-gado dan } \\
\text { Pecel. Dengan bahan utama } \\
\text { sayur-sayur segar dan disajikan } \\
\text { dengan saus yang berbahan dasar } \\
\text { ketela, kacang tanah \& gula } \\
\text { merah. Dilengkapi dengan } \\
\text { sambal dan krupuk puli yang } \\
\text { gurih. }\end{array}$ \\
\hline 2. & Place, Cyberspace and Time & $\begin{array}{l}\text { Biasanya dijual oleh pedagang } \\
\text { keliling gendongan (dijajakan } \\
\text { dengan cara membawa semua } \\
\text { jualannya dengan digendong di } \\
\text { pundak). Beberapa penjual } \\
\text { memilih untuk mangkal di } \\
\text { beberapa sudut kota. }\end{array}$ \\
\hline
\end{tabular}




\begin{tabular}{|c|c|c|}
\hline & & $\begin{array}{l}\text { Disajikan dengan menggunakan } \\
\text { pincuk daun (piring daun) leng- } \\
\text { kap dengan krupuk. Hal ini men- } \\
\text { jadi ciri khas menu Semanggi } \\
\text { tersebut. } \\
\text { Tidak dapat ditentukan waktu } \\
\text { penjual keliling, karena mereka } \\
\text { sendiri tidak memiliki penga- } \\
\text { turan waktu yang terjadwal. }\end{array}$ \\
\hline 3. & Promotion and Education & $\begin{array}{l}\text { Dari pedagang keliling sendiri, } \\
\text { tidak pernah ada strategi promosi } \\
\text { terencana yang dilakukan mau- } \\
\text { pun edukasi bagi para pelanggan } \\
\text { tentang apa dan bagaimana } \\
\text { manfaat mengkonsumsi menu } \\
\text { Semanggi. }\end{array}$ \\
\hline 4. & Price & $\begin{array}{ll}\text { Pedagang keliling menjual } & \text { marga sekitar Rp } \\
\text { dengan harg,-. }\end{array}$ \\
\hline 5 . & Process & $\begin{array}{l}\text { Proses penyajian Semanggi yang } \\
\text { dilakukan oleh penjual keliling, } \\
\text { dinilai kurang higienis secara } \\
\text { kebersihan. Hal ini disebabkan } \\
\text { penjual langsung menggunakan } \\
\text { tangan untuk proses penyajian- } \\
\text { nya tanpa menggunakan sarung } \\
\text { tangan, dan jarang dari mereka } \\
\text { yang membersihkan tangan ter- } \\
\text { lebih dahulu sebelum melakukan } \\
\text { penyajian. }\end{array}$ \\
\hline 6 . & Productivity and Quality & $\begin{array}{l}\text { Dalam hal ini layanan yang di- } \\
\text { transformasikan pada penam- } \\
\text { bahan value produk adalah inter- } \\
\text { aksi langsung antara pembeli de- } \\
\text { ngan pedagang keliling Se- } \\
\text { manggi. Interaksi tersebut biasa- } \\
\text { nya seputar kegiatan berjualan } \\
\text { dari pedagang, selera pembeli } \\
\text { saat mengkonsumsi semanggi } \\
\text { yang saat itu juga dapat dika- } \\
\text { bulkan oleh penjual seperti ting- } \\
\text { kat pedas yang tertentu, penam- } \\
\text { bahan bumbu atau krupuk, dan } \\
\text { lain sebagainya. }\end{array}$ \\
\hline 7. & People & $\begin{array}{l}\text { Pedagang keliling Semanggi } \\
\text { adalah ibu-ibu yang juga } \\
\text { memproduksi menu tersebut. }\end{array}$ \\
\hline
\end{tabular}




\begin{tabular}{|l|l|l|}
\hline 8. & Physical Evidence & Tampilan pakaian dari ibu-ibu \\
& penjual semanggi adalah salah \\
& satu yang sangat unik dan sarat \\
& budaya. Pakaian yang mereka \\
& kenakan masih bergaya pakaian \\
& tradisional lengkap dengan keba- \\
& ya dan jarik (kain batik), lengkap \\
& dengan selendang berbahan kain \\
& tebal yang digunakan untuk \\
& mengikat bakul gendongan. \\
\hline
\end{tabular}

Berdasarkan hasil wawancara dalam penelitian ini, didapatkan bahwa masyarakat sangat kesulitan mencari menu Semanggi di tempat-tempat kuliner (food corner/junction). Hal ini disebabkan penjualan Semanggi selama ini dilakukan dengan cara berjualan keliling, tanpa ada manajemen waktu dalam penjualannya. Sehingga cukup menyulitkan sebagian masyarakat yang ingin menikmati menu tersebut.

Beberapa waktu yang lalu menu Semanggi sempat menjadi ikon menu andalan sebuah hotel bintang lima di Surabaya, namun sayang saat ini menu Semanggi tersebut telah terhapus dari deretan daftar menu. Tergantikan oleh menu lain yang menurut pihak hotel lebih 'menjual' dan mampu menarik pengunjung.

Masyarakat di kalangan anak muda sendiri kurang menyukai menu Semanggi, bahkan diantaranya asing mendengar nama menu tersebut. Mereka jauh lebih mengenal menu Pecel dan Gado-Gado serta tidak banyak dari masyarakat luas yang mengerti dan memahami manfaat dari mengkonsumsi menu ini.

\section{KESIMPULAN}

Modernisme suatu produk sangat diperlukan, karena mengingat peradaban jaman yang banyak berubah berikut dengan selera masyarakat yang juga ikut berubah. Perubahan ini harus diikuti oleh menu-menu tradisional.

Hanya segelintir orang yang mampu 'mengangkat' menu tradisional dalam tatanan modernisme produk. Dalam mengangkat menu tradisional tersebut dibutuhkan strategi marketing yang tepat dan dibutuhkan peran dari berbagai pihak, masyarakat, pemerintah kota dan penggiat bisnis. Tak kalah penting adalah dukungan dari masyarakat, karena menu tradisional tersebut berasal dari masyarakat dan akan kembali pada masyarakat. Dan bagaimana keberadaannya juga akan tergantung dari masyarakat. Pemerintah memiliki kekuatan dan kekuasaan untuk menggerakan kepedulian masyarakat, melalui agenda kegiatan kota dan program lainnya. Harapan terbesar adalah agar kekayaan kuliner bangsa ini tidak musnah dimakan modernisme jaman yang sangat cepat mengaburkan kekhasan budaya bangsa.

\section{SARAN}

Dibutuhkan sederetan strategi yang tepat agar menu Semanggi dapat lagi menjadi menu yang dicari oleh masyarakat luas, diantaranya yaitu :

1. Perlu adanya konsistensi dan komitmen yang tinggi dari para penjual pedagang keliling untuk memiliki waktu dan tempat yang selalu tepat. Hal ini untuk memudahkan para 
pelanggan dalam mencari menu khas Surabaya ini. Seperti halnya salah satu menu khas Surabaya yaitu Lontong Balap yang dapat dengan mudah ditemui di sekitar Jalan Kranggan, karena deretan jalan tersebut berjejer rapi penjual Lontong Balap dengan sajian tradisional.

2. Pemerintah kota Surabaya sendiri perlu turun tangan dalam melestarikan menu tradisional ini. Seperti memberikan fasilitas tempat yang khusus untuk menu tradisional Semanggi. Sama halnya dengan menu khas Surabaya lainnya yaitu Lontong Balap Surabaya. Sehingga memudahkan para wisatawan untuk menuju pada lokasi tersebut.

3. Penjual dan pemerintah atau lembaga kesehatan terkait perlu melakukan edukasi pada masyarakat tentang manfaat kesehatan, jika mengkonsumsi menu Semanggi ini. Hal ini menjadi daya tarik tersendiri bagi sebagian masyarakat.

4. Keberadaan Semanggi harus ada di tengah-tengah masyarakat dengan cara selalu ambil bagian pada agenda kota Surabaya. Seperti pada bazaar menu tradisional, pada saat rangkaian acara ulang tahun kota Surabaya, dan lain sebagainya. Sekali lagi hal ini membutuhkan bantuan dari pemerintah kota untuk dapat memfasilitasi para penjual keliling Semanggi.

\section{DAFTAR KEPUSTAKAAN}

Ferdinand, Augusty Tae, 2000, Manajemen Pemasaran: Suatu Pendekatan Stratejik, Program MM UNDIP, Semarang.
Kotler, Philip, 2005a, Manajemen Pemasaran, PT. Indeks, Jakarta.

Kotler, Philip, Manajemen Pemasaran Analisis Perencanaan, Implementasi dan Kontrol, 2005b, Jilid I dan II, Edisi Kesebelas, PT. Indeks, Jakarta.

Kotler, Philip dan Kevin L. Keller, 2007, Manajemen Pemasaran. PT. Indeks, Jakarta.

Kriyantono, Rachmat, 2006, Tehnik Praktis Riset Komunikasi, Prenada Media Group, Jakarta.

Lovelock, Christopher H. and Lauren K. Wright, 2002, Principles of Service Marketing and Management, Prentice Hall Inc. Upper Saddle River, New Jersey.

Miles dan A. Michael Huberman, 1992, Analisis Data Kualitatif, Universitas Indonesia, Jakarta.

Soegiyono, M., 2007, Metodologi Penelitian Kuantitatif, Kualitatif, CV. Alfabeta, Bandung.

http://beritasurabaya.net/index_sub.ph p? category $=15 \& \mathrm{id}=87$ - diakses pada tanggal 7 Maret 2016.

http://www.cnnindonesia.com/gayahidup/20150715161530-26266604/semanggi-kulinerkeberuntungan-surabaya-yangnyaris-punah/ - diakses pada tanggal 7 Maret 2016. 